
Chargers Framed in Smart Grids,"

YEF-ECE International Young Engineers Forum on Electrical and Computer Engineering, Almada Portugal, May 2019.

This material is posted here with permission of the IEEE. Such permission of the IEEE does not in any way imply IEEE endorsement of any of Group of Energy and Power Electronics, University of Minho, products or services. Internal or personal use of this material is permitted. However, permission to reprint/republish this material for advertising or promotional purposes or for creating new collective works for resale or redistribution must be obtained from the IEEE by writing to pubs-permissions@ieee.org. By choosing to view this document, you agree to all provisions of the copyright laws protecting it. 


\section{Comprehensive Analysis and Experimental Validation of Five-Level Converters for EV Battery Chargers Framed in Smart Grids}

\author{
Vitor Monteiro \\ Industrial Electronics Department \\ ALGORITMI Research Centre \\ University of Minho \\ Campus de Azurem \\ Guimarães, Portugal \\ vmonteiro@,dei.uminho.pt \\ J. C. Aparício Fernandes \\ Industrial Electronics Department \\ ALGORITMI Research Centre \\ University of Minho \\ Campus de Azurem \\ Guimarães, Portugal \\ aparicio@dei.uminho.pt
}

\author{
Tiago J. C. Sousa \\ Industrial Electronics Department \\ ALGORITMI Research Centre \\ University of Minho \\ Campus de Azurem \\ Guimarães, Portugal \\ tsousa@dei.uminho.pt
}

\author{
Carlos Couto \\ Industrial Electronics Department \\ ALGORITMI Research Centre \\ University of Minho \\ Campus de Azurem \\ Guimarães, Portugal \\ ccouto@dei.uminho.pt
}

\author{
Rafael Leite \\ Industrial Electronics Department \\ ALGORITMI Research Centre \\ University of Minho \\ Campus de Azurem \\ Guimarães, Portugal \\ a73417@alunos.uminho.pt
}

\author{
João L. Afonso \\ Industrial Electronics Department \\ ALGORITMI Research Centre \\ University of Minho \\ Campus de Azurem \\ Guimarães, Portugal \\ jla@dei.uminho.pt
}

\begin{abstract}
The electric vehicle (EV) is the foremost element for spreading electric mobility in smart grids. Its integration into the electrical power grid involves the use of battery chargers with improved power quality aspects, and therefore, the topology of the front-end power converter represents a vital role in the EV battery charger (EVBC). Since multilevel topologies offer a set of advantages to accomplish with the power grid interface, a comprehensive investigation of two five-level topologies for EVBCs is presented in this paper. An accurate computational validation and a meticulous explanation of the hardware and software required for the five-level topologies under study is presented and explained considering realistic operating conditions. The obtained results show the pros and cons of each topology targeting EVBC applications for smart grids.
\end{abstract}

Keywords-Five-Level Converter; EV Battery Charger; Power Quality; Smart Grids.

\section{INTRODUCTION}

Energy concerns are emerging as fundamental aspects for sustainability. In terms of mobility, the new paradigm of electric mobility is mainly centralized in the electric vehicle (EV), besides other promises as fuel cell EVs [1][2][3]. Since a plug-in EV has the possibility to consume and store energy from the grid, by using a bidirectional EV battery charger (EVBC), the EV has the capability to return energy back to the grid. The importance of the EV in this perspective is scrutinized in [4], [5], and [6] concerning control and power electronics issues for the grid governing. Since the EVBC is directly connected to the grid, identified as a new electrical appliance capable of a bidirectional power exchange, power quality questions are of the utmost importance, as verified, e.g., in the studies presented in [7], [8], and [9].

Characteristically, the grid side interface of the EVBC is accomplished by two- or three-level structures [10], but using more voltage levels allows to obtain a produced voltage with lower harmonic distortion and, consequently, the requirements of the passives filters can be minimized [11][12]. However, though increasing the levels will imply a reduction in the needs of passive filters, it is not possible to increase the levels indeterminately, because the requirements of hardware and software will also increase proportionately. In this sense, to comply with an acceptable relationship between voltage levels and passive filters, in a strategy to increase power density, structures with five voltage levels are well indicated to be applied in EVBCs. Using five level converters in EVBCs will contribute to reduce the global volume and size of the equipment, while maintaining high power quality levels, signifying a contribution over state-of-the-art solutions. A six switch five level structure based on the well-known NPC converter, aiming renewables as final application, is proposed as new in [13]. Also for solicitations of renewables, five-level structures are suggested in [14] and [15]. Considering motor drives as applications, a new five-level topology is offered in [16]. A Vienna-type structure skilled of five levels is proposed in [17] as an active rectifier. Similarly, but based on a T-type converter, a five-level structure is considered in [18] for smart grids. An active rectifier is proposed in [19], which is capable of producing five-levels and has as final application an EVBC. Also for EVBC applications, a new five-level converter is presented is [20]. Symmetrical and asymmetrical structures of cascade converters are proposed as innovative in [21], realizing a five-level converter.

As previously cited in different studies, not all five-level structures are suitable for applications of EVBCs, as far as the grid-side converter is concerned. More important to highlight is that they were not directly analyzed to each other in order to identify pros and cons of each solution. In this sense, this paper presents a realistic analysis between two topologies of five voltage levels with main focus on EVBCs. These topologies were selected due to the reduced number of components, both are constituted by a single split dc-link, and both are bidirectional in relation to the operation from the grid point of view. Since only five level topologies are considered for analysis, the full-bridge topology is out of analysis. Moreover, galvanic isolation can be guaranteed by the dc-dc converter as a requirement for the automotive industry. As differentiating factors, this paper presents the following aspects: (1) Analysis of two five level topologies (T-type five-level and full-bridge five-level) based on computational 


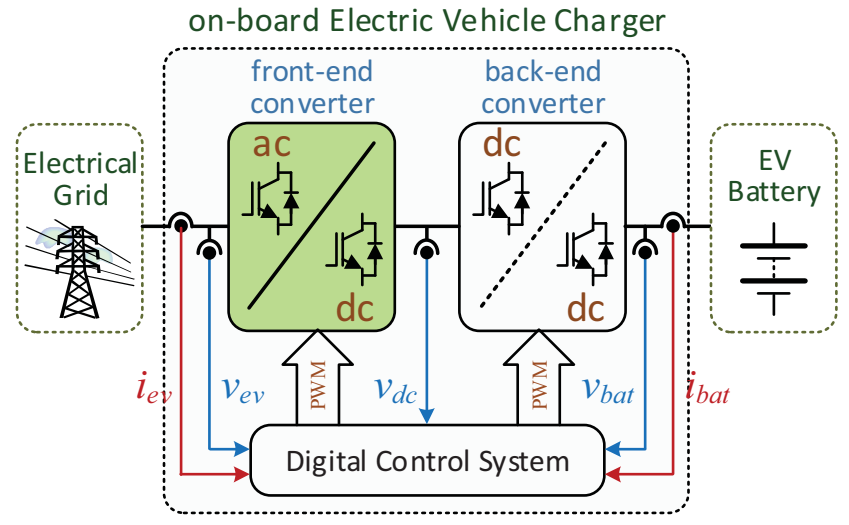

(a)

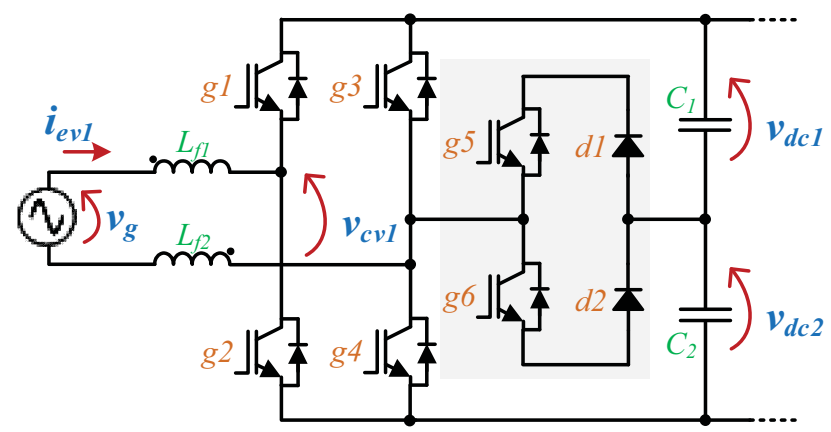

(b)

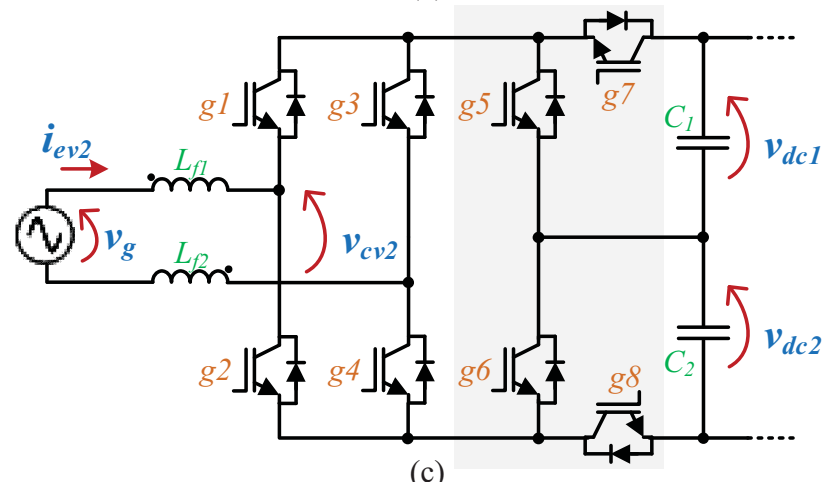

(c)

Fig. 1. Topologies under analysis: (a) Contextualization about the introduction of the front-end converter in an EV charger; (b) T-type five-level topology; (c) Full-bridge five-level topology.

results concerning the controlled variables and the implementation requirements of hardware and software; (2) Experimental validation using two laboratory prototypes of the five level topologies in analysis.

After the introduction and the description of the main contributions, Section II presents the hardware topologies under comparison, Section III presents the laboratory prototypes and an analysis in terms of the hardware and software requirements, Section IV describes the main computer and experimental results about the principle of operation of both topologies, and, finally, Section V ends the paper with the conclusions.

\section{TOPOLOGIES UNDER ANALYSIS: HARDWARE STRUCTURE}

The topologies in analysis are shown in Fig. 1. The contextualization about the introduction of the front-end converter in an EVBC is illustrated in Fig. 1(a). In Fig. 1(b) and Fig. 1(c) are revealed the two five-level topologies under analysis. As shown, both structures are composed by the same number of semiconductors (a more detailed description is presented in Section IV), the same coupling filter, and both have a split dc-link, categorizing an important feature for EVBCs, especially when compared to cascade multilevel structures. A more comprehensive description of each structure is presented in the next sections.

\section{A. T-Type Five-Level Topology}

The T-type structure shown in Fig. 1(b) is composed by six controlled semiconductors, IGBTs in this case, and two diodes. This structure is composed of a fully controlled bridge (IGBTs $g 1$ to $g 4$ ) and a semi controlled bridge (IGBTs $g 5, g 6$ and diodes $d 1, d 2$ ) that allows bidirectional and bipolar operation and it is connected between the neutral terminal of the grid (one of the main bridge legs) and the midpoint of the split dc-link. Instead of this structure of semi controlled bridge, a single structure composed by two IGBTs with a configuration of common emitter can be used (also a common collector configuration of the IGBTs can be used, working with the same principle, but it is not suitable when comparing the required number of isolated power supplies for implementing the IGBTs gate-drivers). This is the main reason why it is identified as T-type structure. According to Table I, by properly selecting the IGBTs that switch in each period of the digital control (i.e., the defined sampling period for controlling the topology), the converter allows to operate in the four quadrants, i.e., in bidirectional mode. Note that the bidirectional functionality is a relevant aspect for EVBCs, since it allows the EV to be dynamically integrated in the grid to operate as a grid-to-vehicle ( $\mathrm{G} 2 \mathrm{~V}$ mode) or as a power supply for the grid, i.e., as vehicle-to-grid (V2G mode). These topics of research are explored in [22] and [23]. In terms of the maximum voltage at which each IGBT is subjected, the IGBTs $g 1, g 2$ must support a $v_{d c}$ voltage, whereas the other IGBTs must support a voltage $v_{d c} / 2$. The diodes must withstand a maximum voltage of $v_{d c} / 2$. It is important to note that during the mode when the EVBC receives power from the grid, the converter can operate with a strategy that only uses some of the IGBTs (e.g., by replacing the IGBTs $g 3$ and $g 4$ by diodes, it is possible to obtain a unidirectional active rectifier, also comprising five voltage levels). Moreover, in this circumstance, the IGBTs $g 1$ and $g 2$ are switched at the grid frequency, contributing for improving the efficiency of the converter.

\section{B. Full-Bridge Five-Level Topology}

As regards the structure shown in Fig. 1(c), it is composed by a traditional, fully controlled H-bridge and by an additional arrangement of four IGBTs to connect the H-bridge and the split dc-link. Equivalently to the previous converter, according to Table II, by properly selecting the IGBTs that switch in each period, this converter also allows to operate in the four quadrants (in the case of applications of EVBCs, for $\mathrm{G} 2 \mathrm{~V}$ and $\mathrm{V} 2 \mathrm{G}$ modes). In terms of the maximum voltage at which each IGBT is subjected, all the IGBTs must support a voltage of $v_{d c} / 2$. Also similarly to the previous converter (topology highlighted in Fig. 1(b)), during the G2V mode, the converter can operate with a strategy that only uses some of the IGBTs (e.g., by replacing the IGBTs $g 3$ and $g 4$ by diodes it is possible to obtain a unidirectional active rectifier with five-levels), where the IGBTs $g 1$ and $g 2$ are switched at the grid frequency. However, the focus of this paper is to compare the two topologies in bidirectional mode, therefore all the IGBTs are necessary. 
TABLE I

Possible States of the T-TyPe Five-LeVEl Topology

\begin{tabular}{|c|c|c|c|c|c|c|c|c|}
\hline & & $g 1$ & $G 2$ & G3 & G4 & G5 & G6 & $V_{C V I}$ \\
\hline \multirow{6}{*}{ ৯্ত } & 0 & OFF & OFF & OFF & OFF & OFF & OFF & $+v d c$ \\
\hline & $\wedge_{\infty}$ & OFF & OFF & OFF & OFF & ON & OFF & $v d c / 2$ \\
\hline & $>$ & OFF & OFF & ON & OFF & OFF & OFF & 0 \\
\hline & 0 & OFF & OFF & OFF & $\mathrm{ON}$ & OFF & OFF & 0 \\
\hline & $V_{0}$ & OFF & OFF & OFF & OFF & OFF & ON & $-v d c / 2$ \\
\hline & & OFF & OFF & OFF & OFF & OFF & OFF & $-v d c$ \\
\hline \multirow{6}{*}{$\underset{N}{\supset}$} & 0 & $\mathrm{ON}$ & OFF & OFF & ON & OFF & OFF 0 & $+v d c$ \\
\hline & $\hat{\wedge}_{\infty}$ & ON & OFF & OFF & OFF & OFF & ON & $v d c / 2$ \\
\hline & & ON & OFF & OFF & OFF & OFF & OFF & 0 \\
\hline & 0 & OFF & ON & OFF & OFF & OFF & OFF & 0 \\
\hline & $V_{\infty}$ & OFF & ON & OFF & OFF & ON & OFF & $-v d c / 2$ \\
\hline & & OFF & ON & $\mathrm{ON}$ & OFF & OFF & OFF & $-v d c$ \\
\hline
\end{tabular}

TABLE II

Possible StATES OF THE FULL-BRIDGE FIVE-LEVEL TOPOLOGY

\begin{tabular}{|c|c|c|c|c|c|c|c|c|c|c|}
\hline & & $g 1$ & $G 2$ & G3 & G4 & G5 & G6 & $G 7$ & $G 8$ & $V_{C V 2}$ \\
\hline \multirow{6}{*}{ ৩ } & \multirow{3}{*}{$\begin{array}{l}0 \\
\Lambda_{\lambda^{\infty}}\end{array}$} & ON & OFF & OFF & ON & OFF & OFF & ON & ON & $+v d c$ \\
\hline & & ON & OFF & OFF & ON & OFF & $\mathrm{ON}$ & ON & OFF & $+v d c / 2$ \\
\hline & & $\mathrm{ON}$ & OFF & OFF & ON & $\mathrm{ON}$ & $\mathrm{ON}$ & OFF & OFF & 0 \\
\hline & \multirow{3}{*}{$\begin{array}{l}0 \\
V \\
\lambda^{\infty}\end{array}$} & OFF & $\mathrm{ON}$ & ON & OFF & $\mathrm{ON}$ & $\mathrm{ON}$ & OFF & OFF & 0 \\
\hline & & OFF & ON & $\mathrm{ON}$ & OFF & ON & OFF & OFF & $\mathrm{ON}$ & $-v d c / 2$ \\
\hline & & OFF & $\mathrm{ON}$ & $\mathrm{ON}$ & OFF & OFF & OFF & $\mathrm{ON}$ & ON & $-v d c$ \\
\hline \multirow{6}{*}{$\stackrel{৩}{>}$} & \multirow{3}{*}{$\begin{array}{l}0 \\
\wedge \\
\lambda^{\infty}\end{array}$} & ON & OFF & OFF & ON & OFF & OFF & ON & ON & $+v d c$ \\
\hline & & $\mathrm{ON}$ & OFF & OFF & ON & OFF & ON & $\mathrm{ON}$ & OFF & $+v d c / 2$ \\
\hline & & $\mathrm{ON}$ & OFF & OFF & ON & $\mathrm{ON}$ & $\mathrm{ON}$ & OFF & OFF & 0 \\
\hline & \multirow{3}{*}{$\begin{array}{l}0 \\
V \\
\lambda^{\infty}\end{array}$} & OFF & $\mathrm{ON}$ & $\mathrm{ON}$ & OFF & $\mathrm{ON}$ & $\mathrm{ON}$ & OFF & OFF & 0 \\
\hline & & OFF & ON & ON & OFF & ON & OFF & OFF & ON & $-v d c / 2$ \\
\hline & & OFF & ON & ON & OFF & OFF & OFF & $\mathrm{ON}$ & ON & $-v d c$ \\
\hline
\end{tabular}

\section{TOPOLOGIES UNDER ANALYSIS:}

\section{LABORATORY PROTOTYPES}

The structures of the converters that are being analyzed in the scope of this paper were validated using two laboratory prototypes, in which the final objective is the application in a bidirectional system of an EVBC. In Fig. 2 are presented the photographs of each prototype in the laboratory workbench, namely in Fig. 2(a) the photograph of the T-type five level topology and in Fig. 2(b) the photography of the full-bridge five-level topology.

In terms of main characteristics, which are common to both prototypes, simple inductive filters were considered in the grid side with a value of $5 \mathrm{mH}$ (for a current of $20 \mathrm{~A}$ ), IGBTs FGA25N120ANTD (switched at $20 \mathrm{kHz}$ ), dc-link capacitors of $2 \mathrm{mF}$ (for a voltage of $450 \mathrm{~V}$ ), isolated HCPL3120 as gate-drivers (with isolated power supplies TMA1515), and the DSP F28335 for each case of prototype. Besides, both converters were tested directly to the power grid with a transformer, obtaining a nominal voltage of $115 \mathrm{~V}$ (which is an acceptable voltage level, similar to the voltage level of several countries around the world) and frequency of $50 \mathrm{~Hz}$.

\section{TOPOLOGIES UNDER ANALYSIS:}

\section{COMPUTER AND EXPERIMENTAL RESULTS}

The principle of operation, in terms of the controlled variables of both converters, is shown in Fig. 3. This result was obtained using a simulation model implemented in PSIM. The simulation model was developed focusing on an actual application, therefore, for that reason, the harmonic distortion of the measured voltage in a real environment in the laboratory was considered (using a Fluke equipment, model

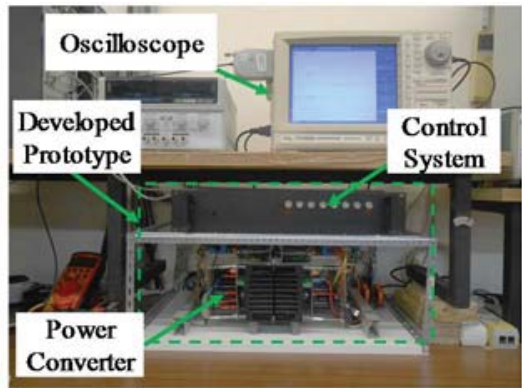

(a)

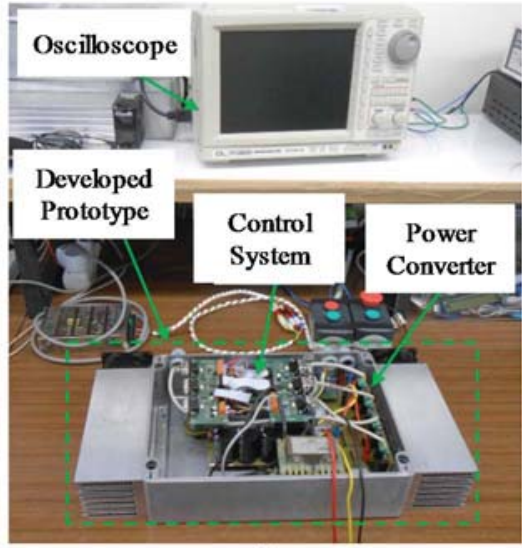

(b)

Fig. 2. Photograph of each laboratory prototype: (a) T-type five-level topology; (b) Full-bridge five-level topology.

435). For the control of the converters, a predictive strategy was chosen (and programmed in the DSPs for the experimental validation); however, other control techniques can be used to obtain results with another type of performance (depending of the application requirements). As the purpose of this paper is not to compare the control techniques applied to the converters in analysis, the implementation details concerning the control have been hidden in this paper, but can be reviewed in the original publications [24][25].

In order to confirm and analyze the main functionalities of both converters, Fig. 3 is divided into four distinct steps. In Fig. 3(a), during the first step (\#1), both converters present a sinusoidal waveform in the input current (ac side controlled current), which corresponds to the operation of the converters when they receive power from the grid (active rectifier in $\mathrm{G} 2 \mathrm{~V}$ ). Even when operating as an active rectifier, from this first stage to the second stage (\#2), there is a sudden change in the operation of the converters. This sudden change has been intensely simulated, because it may correspond to a change of the current on the battery side during the charging, which forces to change the operating power of the EVBC. Consequently, the reference of the ac-side current changes and, due to the applied control, the current effectively measured also changes (as the rms value of the grid voltage is the same, the operating power will change due to the variation of the ac side current). In order to really check the behavior of both converters, a sudden change of $50 \%$ less than the nominal power was chosen. This abrupt change of 50\% was considered only for an effective validation of the converters, although in a real application of an EVBC, there would not exist such abrupt changes. As this is a critical point of operation for the converters, this transition to $50 \%$ of the rated operating power is shown in zoom, so that the current in each converter can be verified in detail. This detail is highlighted in Fig. 3(b). As it turns out, both currents are quite similar, only 


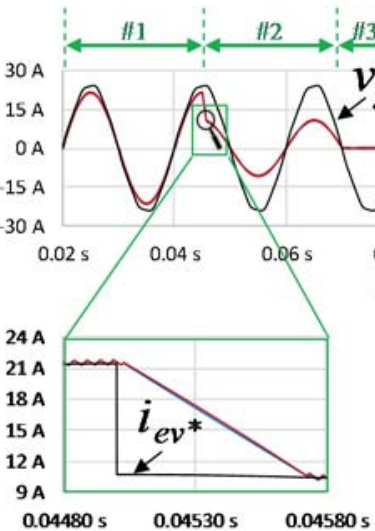

(b)

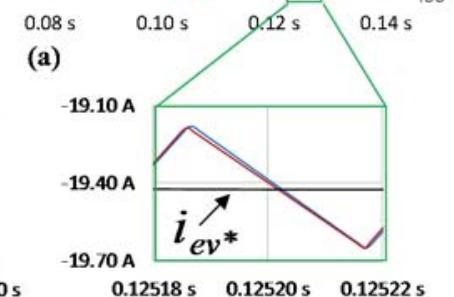

(c)

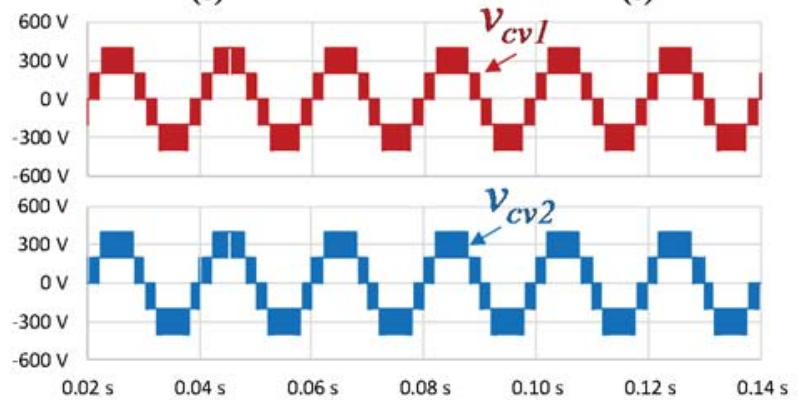

(d)

Fig. 3. Simulation results of the topologies under analysis: (a) Grid-side currents of both topologies ( $i_{e v 1}$ for the T-type converter and $i_{e v 2}$ for the full-bridge converter); (b) Comparative detail of both currents during G2V mode; (c) Comparative detail of both currents during V2G mode; (d) Voltage produced by the T-type five-level converter $\left(v_{c v l}\right)$ and voltage produced by the full-bridge five-level converter $\left(v_{c v 2}\right)$.

presenting slight differences in terms of delay. Subsequently, in step three (\#3), the EVBC becomes inactive in relation to the grid, neither receiving $(\mathrm{G} 2 \mathrm{~V})$ nor providing power $(\mathrm{V} 2 \mathrm{G})$. Based on the principle that the final application of the converters is an EVBC, this step was only considered as a transition between the $\mathrm{G} 2 \mathrm{~V}$ mode (the $\mathrm{EV}$ receives power from the grid, where the converter acts as an active rectifier) and the $\mathrm{V} 2 \mathrm{G}$ mode (the EV provides power to the grid, where the converter acts as an inverter).

In the fourth step (\#4), instead of receiving energy, the EV is injecting energy into the grid. This stage was considered in the simulation because it is specially dedicated to support the grid using the energy stored in the EV. Therefore, since it is not necessary to inject power in the grid instantaneously at the nominal power, a progressive increase of the injected power, from zero to the nominal power, was considered in the simulation. In order to verify, in simulation, the transition from zero to the nominal power, it was considered that the transition took place in a few milliseconds, however, in a practical implementation this transition can be performed more smoothly, depending on the needs of the grid in terms of injected power. Also in this step, a zoom of both currents was considered, corresponding to the zone when the converters are operating in the fourth quadrant (positive voltage and negative current), i.e., as grid tie inverter controlled by current. This detail is presented in Fig. 3(c). Once again it is noted that the controlled currents are quite similar, only differing slightly in the delay of one with respect to another. Although the question of delaying one current relative to another may be significant for some more sensitive applications, when the final application is an EVBC, as is the case in this paper, this issue is not significant for the system

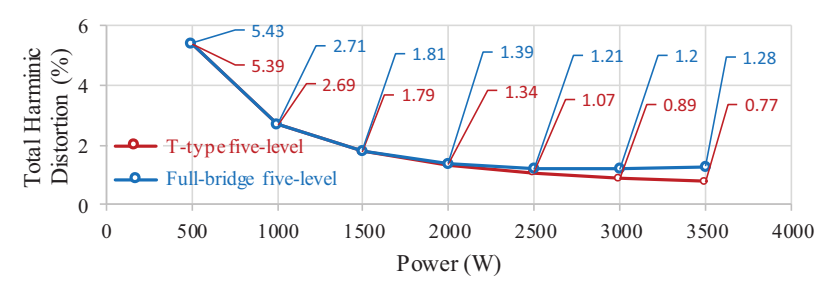

Fig. 4. Simulation results of the topologies under analysis: Total harmonic distortion (THD) for a range of operating power from $500 \mathrm{~W}$ to $3500 \mathrm{~W}$.

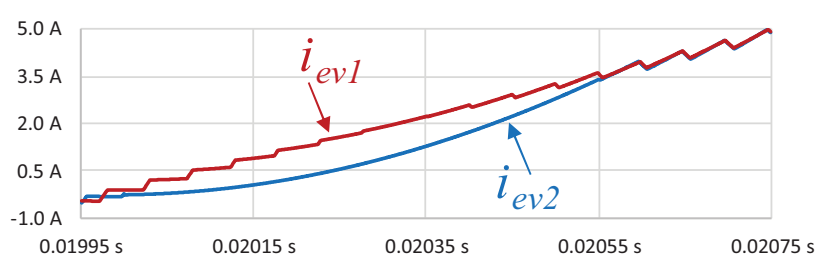

Fig. 5. Simulation results of the topologies under analysis: Detail of the grid-side current during the passage through zero.

operation. It is also interesting to note that the voltage produced by the converters does not change, as shown in Fig. 3(d), respectively for the converters illustrated in Fig. 1(b) and Fig. 1(c).

As analyzed in Fig. 3, there are no significant differences in terms of the controlled currents of both topologies. The same happens when both currents are compared in terms of total harmonic distortion (THD) for several operating powers. In this sense, an analysis was performed in terms of THD, and the results obtained are presented in the graph of the Fig. 4. These results were obtained for a minimum power of $500 \mathrm{~W}$ and a maximum power of $3500 \mathrm{~W}$ (defined as maximum value for the operating power of the EVBC), with measuring intervals of $500 \mathrm{~W}$. As it can be seen, by increasing the operating power, the difference of THD is accentuated, where the converter of the Fig. 1(c) presents slightly better results than the converter of the Fig. 1(b), although the difference is only $0.51 \%$. The main difference between the two grid side currents, which gives rise to the THD difference, is related to the transition from the positive half cycle to the negative half-cycle (and vice-versa), where the voltage levels produced by the converters differ slightly, but enough to cause the current distortion. This difference is more accentuated as the operating power increases, because the ways to produce the different voltage levels of each converter are distinct (cf. Table I and Table II), causing slight differences in the current obtained. In Fig. 5, a detail of both currents during zero crossing is presented. The current of the converter shown in Fig. 1(b) shows a slightly higher distortion, resulting in a difference in the obtained values of THD (cf. Fig. 4). The reference of current is exactly the same for both converters, meaning that this is not the reason for the difference in the obtained THD.

In addition to the technical analysis, the converters were also analyzed in terms of needs for a practical implementation. In order to obtain an objective comparative analysis, the voltage levels, the number of IGBTs, the number of diodes, the number of gate-driver circuits for the IGBTs, the number of dc-link capacitors, and the number of sensors were considered for comparison. Based on the principle that both converters produce five levels and have a dc-link with a single midpoint structure, the main differences lie in the number of used semiconductors (IGBTs and diodes) and their gate-driver circuits (in case of IGBTs). The converter shown 


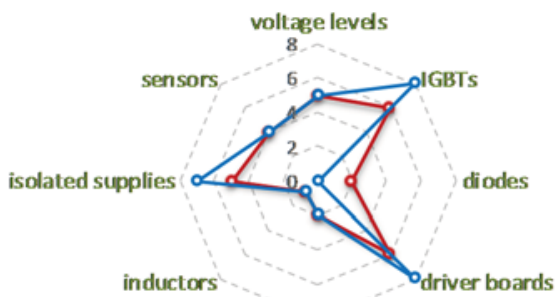

capacitors

- - T-typefive-kvel $\quad-$ Full-bridge five-level

Fig. 6. Comparative chart in terms of the main requirements for the implementation of the topologies under analysis:



Fig. 7. Experimental results of the T-type converter during G2V mode: Grid-side current $\left(i_{e v l}\right)$; Grid-side voltage $\left(v_{g}\right)$; Voltages in the dc-link $\left(v_{d c l}\right.$, $\left.v_{d c 2}\right)$; Produced voltage $\left(v_{c v 1}\right)$.

in Fig. 1(b) requires less two IGBTs and their gate-drivers (as well as less two isolated power supplies), but requires two additional diodes. Taking into account these aspects, and also the needs of the control circuit for the additional IGBTs, the converter shown in Fig. 1(b) (T-type five-level) is more advantageous than the converter shown in Fig. 1(c) (full-bridge five-level). This difference can be even more prominent if the bidirectional and bipolar cell (formed by the IGBTs $g 5, g 6$ and by the diodes $d 1, d 2$ ) consists of only two IGBTs with common emitter configuration, where the two diodes are not needed and only one gate-driver circuit can be sufficient for controlling both IGBTs. A comparative chart of both converters, considering the above referenced strands, is shown in Fig. 6.

As regards dead-time control, the converter shown in Fig. 1(b) needs more requirements than the converter shown in Fig. 1(c). For the converter of Fig. 1(c) it is necessary to guarantee dead-time between each leg $(g 1, g 2$ and $g 3, g 4)$ and between the IGBTs $g 5, g 7$ and also $g 6, g 8$. In this way, it is possible to implement a simple PWM control strategy in which each channel is composed of a signal and its complementary with dead-time between them (four sets of PWMs with complementary). For the converter of Fig. 1(b), the guarantee of dead-time between the IGBTs is more demanding, because in addition to the dead-time between the IGBTs of the same leg $(g 1, g 2$ and $g 3, g 4)$ it is necessary to guarantee dead-time between the IGBTs $95, g 6$ with the IGBTs $g 3, g 4$ of one of the legs. Thus, besides the dead-time between the IGBTs $g 1, g 2$, it must be controlled between three IGBTs, $g 3, g 4$ and $g 5$ and also between $g 3, g 4$ and $g 6$, significantly increasing the complexity of the control.

In terms of experimental validation, both converters were validated separately, as shown on the workbenches in Fig. 2.

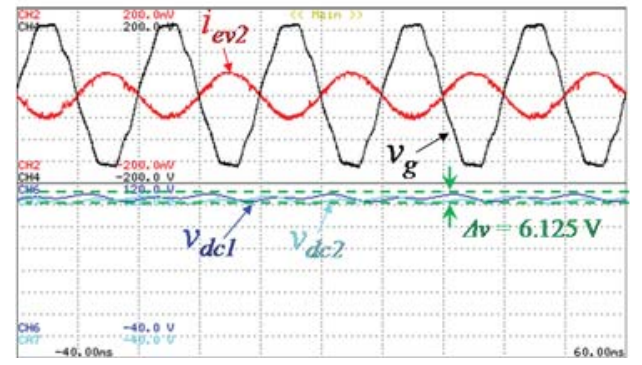

Fig. 8. Experimental results of the full-bridge converter during V2G mode: Grid-side current $\left(i_{e v 2}\right)$; Grid-side voltage $\left(v_{g}\right)$; Voltage variation in the dc-link $\left(v_{d c 1}, v_{d c 2}\right)$

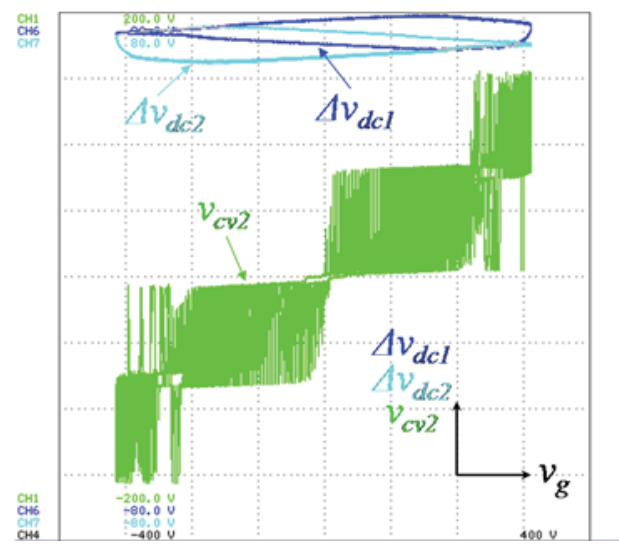

Fig. 9. Experimental results of the full-bridge converter during V2G mode: Produced voltage $\left(v_{d c 2}\right)$ and voltage variation in the dc-link $\left(\Delta v_{d c 1}, \Delta v_{d c 2}\right)$ as function of the grid-side voltage $\left(v_{g}\right)$.

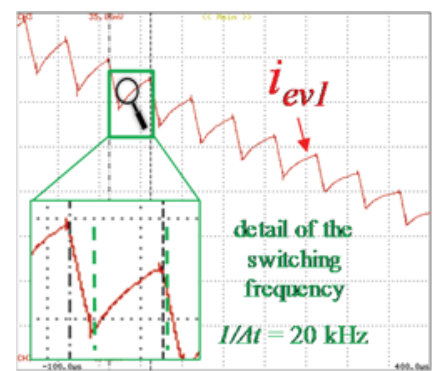

(a)

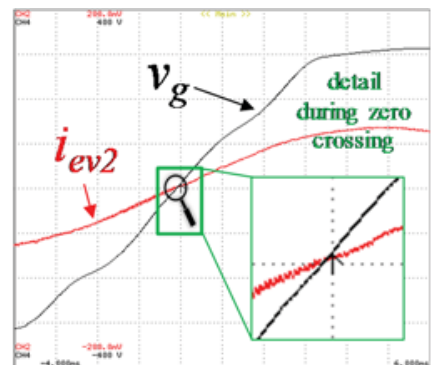

(b)
Fig. 10. Experimental results: (a) Switching frequency detail of the T-type converter grid-side current $\left(i_{e v 1}\right)$; (b) Detail of the grid-side current $\left(i_{e v 2}\right)$ and voltage $\left(v_{g}\right)$ during the passage through zero of the full-bridge converter.

As the results obtained for both converters are very similar (both with five-levels and with sinusoidal current), instead of presenting similar results, it was chosen to present different results for each converter (in G2V and V2G), but corroborating the principle of operation in terms of voltage and current. Thus, for the converter presented in Fig. 1(b), Fig. 7 shows the grid side current in order to verify that it has a sinusoidal waveform (in this particular case during the G2V mode), the voltages relating to the two capacitors of the dc-link (where each one is controlled in each half-cycle of the grid voltage), and the measured voltage downstream the coupling filter (voltage produced by the converter) is exhibited to verify that it has the expected five-levels. On the other hand, to avoid repeating similar results for the converter of Fig. 1(c), in Fig. 8 the current in the grid side is also shown to verify the waveform (in $\mathrm{V} 2 \mathrm{G}$ mode, i.e., in opposition to the voltage), and the voltage ripple on each capacitor of the dc-link. Also in relation to this converter, Fig. 9 shows an experimental result that relates the voltage in each capacitor, 
the voltage produced by the converter (downstream the coupling filter) and the grid voltage. Fig. 10 shows a detail of the current of each converter. Thus, with respect to the T-type converter (Fig. 1(b)), Fig. 10(a) is intended to validate the ripple and the switching frequency $(20 \mathrm{kHz})$ of the current $\left(i_{\text {evl }}\right)$. With respect to the full-bridge converter (Fig. 1(c)), Fig. $10(\mathrm{~b})$ it is intended to verify when the current $\left(i_{e v 2}\right)$ crosses the voltage $\left(v_{g}\right)$.

\section{CONCLUSIONS}

This paper presents an analysis of two front-end converters for electric vehicle (EV) chargers: A T-type five-level and a full-bridge five-level. Based on the principle that the integration of electric mobility in the power grid involves needs of operation with high standards of power quality, the converters under analysis are of multilevel type, each one capable of producing five voltage levels. In addition, both converters allow operating in bidirectional mode with controlled current, a strand that will be of paramount importance for future smart grids with EVs. This framework with the power grid is described in detail throughout the paper, and it is corroborated by computational and experimental results. The results show that in terms of grid-side current control, the differences are not significant for applications of EV battery chargers (EVBC). On the other hand, in terms of controllability, the T-type five-level is more complex than the full-bridge five-level, mainly concerning the dead-time requirements. In terms of practical implementation of both solutions in EVBCs applications, as regards the necessary components and the requirements of the control hardware, the differences are more noticeable and may be decisive for choosing one of the solutions, where the T-type five-level requires less components than the full-bridge five-level, also presenting slightly better results in terms of power quality. Two laboratory prototypes are presented to support the analysis presented.

\section{ACKNOWLEDGMENT}

This work has been supported by FCT - Fundação para a Ciência e Tecnologia within the Project Scope: UID/CEC/00319/2019. This work has been supported by FCT Project newERA4GRIDs - New Generation of Unified Power Conditioner with Advanced Control, Integrating Electric Mobility, Renewables, and Active Filtering Capabilities for the Power Grid Improvement: POCI-010145-FEDER-030283. Mr. Tiago Sousa is supported by the doctoral scholarship SFRH/BD/134353/2017 granted by the Portuguese FCT agency.

\section{REFERENCES}

[1] Idaho National Laboratory, "Charging and Driving Behavior of Nissan Leaf Drivers in The EV Project with Access to WorkplaceCharging," EV Project, pp.1-4, Nov. 2014.

[2] Roland Matthé, UlrichEberle, "The Voltec System - Energy Storage and Electric Propulsion," ELSEVIER Lithium-Ion Batteries Advances and Applications, pp.151-176, 2014.

[3] Carla B. Robledo, Vincent Oldenbroek, Francesca Abbruzzese, Ad J. M. van Wijk, "Integrating a hydrogen fuel cell electric vehicle with vehicle-to-grid technology, photovoltaic power and a residential building," ELSEVIER Applied Energy, vol.215, pp.615-629, Apr. 2018.

[4] Albert G. Boulanger, Andrew C. Chu, Suzanne Maxx, David L. Waltz, "Vehicle Electrification: Status and Issues," Proceedings of the IEEE, vol.99, no.6, pp.1116-1138, June 2011.

[5] Kaushik Rajashekara, "Present Status and Future Trends in Electric Vehicle Propulsion Technologies," IEEE J. Emerg. Sel. Topics Power Electron., vol.1, no.1, pp.3-10, Mar. 2013.
[6] Joshua Milberg, Ann Schlenker, "Plug into the Future," IEEE Power Energy Mag., vol.9, no.1, pp.56-65, Feb. 2011.

[7] Vitor Monteiro, João C. Ferreira, Andres A. Nogueiras Melendez, Carlos Couto, João L. Afonso, "Experimental Validation of a Novel Architecture Based on a Dual-Stage Converter for Off-Board Fast Battery Chargers of Electric Vehicles," IEEE Trans. Veh. Tech., vol.67, no.2, pp.1000-1011, Feb. 2018.

[8] Malabika Basu, Kevin Gaughan, Eugene Coyle, "Harmonic distortion caused by EV battery chargers in the distribution systems network and its remedy," International Conference UPEC - Universities Power Engineering Conference, pp.869-873, Jan. 2004.

[9] Vítor Monteiro, J. G. Pinto, João L. Afonso, "Operation Modes for the Electric Vehicle in Smart Grids and Smart Homes: Present and Proposed Modes," IEEE Trans. Veh. Tech., vol.65, no.3, pp.10071020, Mar. 2016.

[10] Noreen Wong, Mehrdad Kazerani, "A Review of Bidirectional OnBoard Charger Topologies for Plug-In Vehicles," IEEE CCECE Canadian Conference on Electrical \&amp; Computer Engineering, pp.1-6, May 2012.

[11] Jun Mei, Bailu Xiao, Ke Shen, Leon M. Tolbert, Jian Yong Zheng, "Modular Multilevel Inverter with new Modulation Method and its Application to Photovoltaic Grid-Connected Generator," IEEE Trans. Power Electron., vol.28, no.11, pp.5063-5073, Nov. 2013.

[12] Leon M. Tolbert, Fang Zheng Peng, Thomas G. Habetler, "Multilevel Converters for Large Electric Drives," IEEE Trans. Ind. Appl., vol.35, no.1, pp.36-44, Jan. 1999.

[13] Hongliang Wang, Lei Kou Yan-Fei Liu, Paresh C. Sen, "A New SixSwitch Five-Level Active Neutral Point Clamped Inverter for PV Applications," IEEE Trans. Power Electron., vol.32, no.9, pp.67006715, Sept. 2017.

[14] Maha G. Elsheikh, Mahrous E. Ahmed, Emad Abdelkarem, Mohamed Orabi, "Single-Phase Five-Level Inverter with Less Number of Power Elements," IEEE INTELEC International Telecommunications Energy Conference, pp.1-8, Oct. 2011

[15] Abdel Hamid Loukriz, Sandra Dudley, Terence Quinlan, Stuart D. Walker, "Experimental Realization of a Single-Phase Five Level Inverter for PV Applications," IEEE COMPEL Control and Modeling for Power Electronics, pp.1-6, June 2016.

[16] Kui Wang, Lie Xu, Zedong Zheng, Yongdong Li, "Capacitor Voltage Balancing of a Five-Level ANPC Converter Using Phase-Shifted PWM," IEEE Trans. Power Electron., vol.30, no.3, pp.1147-1156, Mar. 2015.

[17] Vítor Monteiro, Andrés A. Nogueiras Meléndez, João L. Afonso, "Novel Single-Phase Five-Level VIENNA-Type Rectifier with Model Predictive Current Control,“ IEEE IECON Industrial Electronics Conference, pp.6413-6418, Nov. 2017.

[18] Petar Grbovic, Alessandro Lidozzi, Luca Solero, Fabio Crescimbini, "Five-Level Unidirectional T-Rectifier for High Speed Gen-Set Applications," IEEE Trans. Ind. Appl., vol.52, no.2, pp.1642-1651, Mar. 2016.

[19] Vítor Monteiro, Andrés A. Nogueiras Meléndez, João C. Ferreira, Carlos Couto, João L. Afonso, "Experimental Validation of a Proposed Single-Phase Five-Level Active Rectifier Operating with Model Predictive Current Control,“ IEEE IECON Industrial Electronics Conference, pp.3939-3944, Nov. 2015.

[20] Vitor Monteiro, J. G. Pinto, Tiago J. C. Sousa, Andrés A. Nogueiras Meléndez, João L. Afonso, "A Novel Single-Phase Five-Level Active Rectifier for On-Board EV Battery Chargers," IEEE ISIE International Symposium on Industrial Electronics, vol.4, pp.582-587, June 2017.

[21] Ataollah Mokhberdoran, Ali Ajami,"Symmetric and Asymmetric Design and Implementation of New Cascaded Multilevel Inverter Topology," IEEE Trans. Power Electron., vol.29, no.12, pp.6712-6724, Dec. 2014

[22] Ming Zeng, Supeng Leng, Yan Zhang, "Power Charging and Discharging Scheduling for V2G Networks in the Smart Grid," IEEE ICC International Conference on Communications Workshops, pp.1052-1056, June 2013.

[23] Chunhua Liu, K. T. Chau, Diyun Wu, Shuang Gao, "Opportunities and Challenges of Vehicle-to-Home, Vehicle-to-Vehicle, and Vehicle-toGrid Technologies," Proc. IEEE, vol.101, no.11, pp.2409-2427, Nov. 2013.

[24] Vítor Monteiro, João C. Ferreira, Andrés A. Nogueiras Meléndez, João L. Afonso, "Model Predictive Control Applied to an Improved FiveLevel Bidirectional Converter," IEEE Trans. Ind. Electron., vol.63, no.9, pp.5879-5890, Sept. 2016.

[25] Rafael Leite, João L. Afonso, Vítor Monteiro, "A Novel Multilevel Bidirectional Topology for On-Board EV Battery Chargers in Smart Grids," MDPI Energies, vol.11, no.12, pp.1-21, Dec. 2018. 